\title{
Réforme du régime de responsabilité financière des comptables publics
}

La réforme de la responsabilité financière des ordonnateurs et des comptables est à l'ordre du jour comme en témoigne l'extrait ci-dessous du document issu du $3^{e}$ Comité interministériel de la transformation publique. En effet, le système issu de la loi du 28 décembre 2011 n'est guère satisfaisant mais difficile à réformer : les points de vue des parties prenantes (ministère des finances, comptables publics, juridictions financières...) sont divergents et les tensions sont fortes entre la tradition française de contrôle juridictionnel des comptes et les exigences élémentaires d'efficacité, de modernité et de simplicité de la gestion publique. Après de nombreux autres articles et points de vue, nous publions trois opinions contrastées sur ce sujet sensible et invitons nos lecteurs à poursuivre le débat.

Michel Le Clainche.

\section{Encadré 1}

$3^{\mathrm{e}}$ comité interministériel de la transformation publique, 20 juin 2019 Extrait du document "Bilan et perspectives »

Mettre en place un nouveau régime de responsabilité financière des ordonnateurs et des comptables publics : ce dispositif jamais revu en profondeur depuis le XIXe siècle, alors même que les progrès de l'informatique ont été considérables, est jugé par tous comme peu efficace, inéquitable et contreproductif. II ne répond pas aux objectifs d'une gestion publique efficiente. $C^{\prime}$ est pour répondre à ce constat partagé que le Gouvernement a engagé une réflexion sur la responsabilité financière du comptable public et de l'ordonnateur. II travaillera avec la Cour des Comptes à la mise en place d'un nouveau régime qui corrige les effets négatifs de la responsabilité personnelle et pécuniaire du comptable et vise à une plus forte responsabilité des gestionnaires publics, corollaire indispensable de l'assouplissement des contrôles.

\section{Encadré 2}

\section{Sur la responsabilité personnelle et pécuniaire des comptables publics,} Gestion \& finances publiques a publié au cours des années récentes:

\section{En 2015 :}

Un dossier : La réforme de la RPP : premier bilan, GFP n5/6, pp. 61-87

Un dossier: La réforme de la RPP des comptables publics : regards croisés, GFP n 11/12, pp. 7488

\section{En 2016 :}

La réforme de la responsabilité du comptable public et ses conséquences jurisprudentielles, Stéphanie Damarey, GFP n² 2, pp.42-49

\section{En 2017 :}

Les incertitudes nées de I 'application de la réforme du régime de responsabilité personnelle et pécuniaire des comptables publics, Jean-Luc Girardi, GFP n² 2, pp.89-96

Responsabilité des comptables publics et management public, Michel le Clainche, GFP $n^{\circ} 5$, pp. 98-105

\section{En 2018 :}

La responsabilité des comptables publics : une assurance raisonnable de régularité des comptes ? Philippe Dufresnoy, GFP n², pp. 102-104.

Les propositions du Premier président de la Cour des comptes pour une rénovation du système de responsabilité financière, Didier Migaud, GFP $n^{\circ} 4$

Et dans chaque numéro :

La chronique de jurisprudence de la Cour des comptes de Stéphanie Damarey et Xavier Vandendriessche ou la chronique de jurisprudence des chambres régionales des comptes de Jean-Luc Girardi et Pierre Rocca. 


\section{Le Conseil d'État et la Cour des comptes}

organisent un colloque sur

\section{La responsabilité des gestionnaires publics le 18 octobre de $9 \mathrm{~h}$ à $13 \mathrm{~h}$ à la Cour des comptes}

Inscriptions gratuite avant le 11 octobre : colloque.cour.conseil@ccomptes.fr

\section{$8 \mathrm{~h} 30$ : Café d'accueil}

\section{$9 \mathrm{~h} 00$ : OUVERTURE}

- Didier Migaud, Premier président de la Cour des comptes

9h20 : TABLE RONDE $N^{\circ} 1:$ Quelle responsabilité aujourd'hui pour les gestionnaires publics, regards croisés?

- Modérateur : Jean Gaeremynck, président de la section des finances du Conseil d'État

- Participants :

- Isabelle Falque-Pierrotin, conseillère d'État, ancienne membre du collège des garants du Grand Débat National

- Marie-Anne Levêque, secrétaire générale des ministères de l'éducation nationale, de l'enseignement supérieur et de la recherche

- Fabienne Keller, députée européenne

- Thomas Cazenave, délégué interministériel à la transformation publique

- Raoul Briet, président de chambre à la Cour des comptes

\section{$10 \mathrm{~h} 50$ : CONCLUSION INTERMÉDIAIRE ET TRANSITION}

- Catherine Hirsch de Kersauson, procureure générale près la Cour des comptes

- Jean-Denis Combrexelle, président de la section du contentieux du Conseil d'État

$11 \mathrm{~h} 10$ : TABLE RONDE $N^{\circ} 2$ : Quelle(s) responsabilité(s) pour demain dans la sphère publique?

- Modératrice : Michèle Pappalardo, présidente de chambre, rapporteure générale de la Cour des comptes

- Participants :

- Éliane Houlette, procureure de la République

- Stéphanie Damarey, professeure à l'université de Lille

- Pierre-Louis Mariel, directeur régional des finances publiques d'île-de-France

- Gilles Carrez, député

- Rémi Bouchez, président adjoint de la section des finances du Conseil d'État

\section{$12 \mathrm{~h} 40$ : CONCLUSION}

- Bruno Lasserre, vice-président du Conseil d'État 